\title{
Design of Flue Gas-Air Heat Exchanger for Regeneration of Desiccant System
}

\author{
Shaymaa H. Abdulmalek ${ }^{1}$, Hussain H. Al-Kayiem ${ }^{1, *}$, Aklilu T. Baheta and Ali A. Gitan ${ }^{2}$ \\ ${ }^{1}$ Solar Thermal Advanced Research Center, Universiti Teknologi PETRONAS,32610 Bandar Seri \\ Iskandar, Perak, Malaysia. \\ ${ }^{2}$ Tikrit University, Faculty of Engineering, Mechanical Engineering Department, Tikrit.
}

\begin{abstract}
Heat recovering from biogas waste energy requires robust heat exchanger design. This paper presents the design of fuel gas-air heat exchanger (FGAHE) for recovering waste heat from biogas burning to regenerate desiccant material. Mathematical model was built to design the FGAHE based on logarithmic mean temperature difference (LMTD) and staggered tube bank heat transfer correlations. MATLAB code was developed to solve the algorithm based on overall heat transfer coefficient iteration technique. The effect on tube diameter on design and thermal characteristics of FGAHE is investigated. The results revealed that the smaller tube diameter leads to smaller heat transfer area and tube. On the other hand, the overall heat transfer coefficient and Nusselt numbers have larger rates at smaller tube diameter. In conclusion, the nominated tube diameter for FGAHE is the smaller diameter of $0.0127 \mathrm{~m}$ due to the high thermal performance.
\end{abstract}

\section{Introduction}

Efficient and economic thermal energy gained from the biomass waste, for drying application, requires specific thermal backup unit (TBU) and robust design of heat exchanger [1-3]. Basically, transferring heat from flue gas (the hot fluid) to air (the cold fluid) needs efficient gas-gas heat exchanger that maximize the utilization of thermal load in the flue gases. Based on previous works, the challenge of designing appropriate flue gas-air heat exchanger (FGAHE) for recovering waste biomass energy used to regenerate desiccant material is still under investigation and development.

Many previous researches had presented different designs of heat exchanger for different applications such as reactivation the silica gel by solar energy $[4,5]$. On the other hand, during the absence of solar energy the alternative source of the thermal energy is the biomass in this trend many other researchers investigate the using of west biomass to introduce hot air [3, 6-8]. In an industrial application, the silica gel is regenerated by using fossil full like electrical heater at $140{ }^{\circ} \mathrm{C}$. Solar energy was used to regenerate the silica gel through a heat exchanger during the day time and after the sun hour using the flue gas from the thermal back up unit by using gas to gas heat exchanger [3, 9-12].

\footnotetext{
${ }^{*}$ Corresponding author: hussain kayiem@utp.edu.my
} 
The performance of heat exchanger studied experimentally and theatrically by investigating flue gas heat recovery via condensing heat exchanger [13]. A theatrical analysis was carried out with an optimization of a gas-to-gas heat exchanger with a non-constant cross sectional area [14]. The results obtained from the modelling demonstrate the premise that it is possible to realize designs for heat exchangers that are highly exergy-efficient and very cheap. The design of the heat exchanger has a significate effect on the performance. An experimental study was conducted on tube bank with multi-row staggered tube bundle heat exchangers [10]. The effects of the flue gas velocity, water vapor volume fraction, cooling water flow rate, cooling water temperature and cooling water flow arrangement (series or parallel) on the condensate capture rate and heat transfer coefficient were presented and discussed. Numerical analysis on the performance of the heat exchanger was developed using a new simulation model [11]. In other work, the capacities of heat exchanger was improved using micro heat exchanger [6] . A set of control volumes that include the finned surfaces of both the cold and hot sides (separated by a wall) were detected [15-17].

The objective of the current work is to present the influence of the design parameters on the system thermal performance. The flue gas-air heat exchanger (FGAHE) consisted of tube bank heat exchanger for heat recovery from waste heat of burning biomass. Also, this research aims to investigate the effect of tube diameter on other design and performance aspects of(FGAHE). For efficient operation of desiccant system in the drying system needed to regenerate continuously. In the present work the tube bank cross flow heat exchanger is a suggested choice among various heat exchanger types.

\section{Physical and mathematical modelling of FGAHE}

The physical model of FGAHE for heat recovery from biomass waste energy to regenerate desiccant material for air drying purpose is shown in Fig. 1 which depicts the designed tube bank cross flow heat exchanger. The air enters the FGAHE and flows inside the tubes while the hot flue gas flows over the staggered tubes. The width of the tube bank (w) represents the length of the tubes.
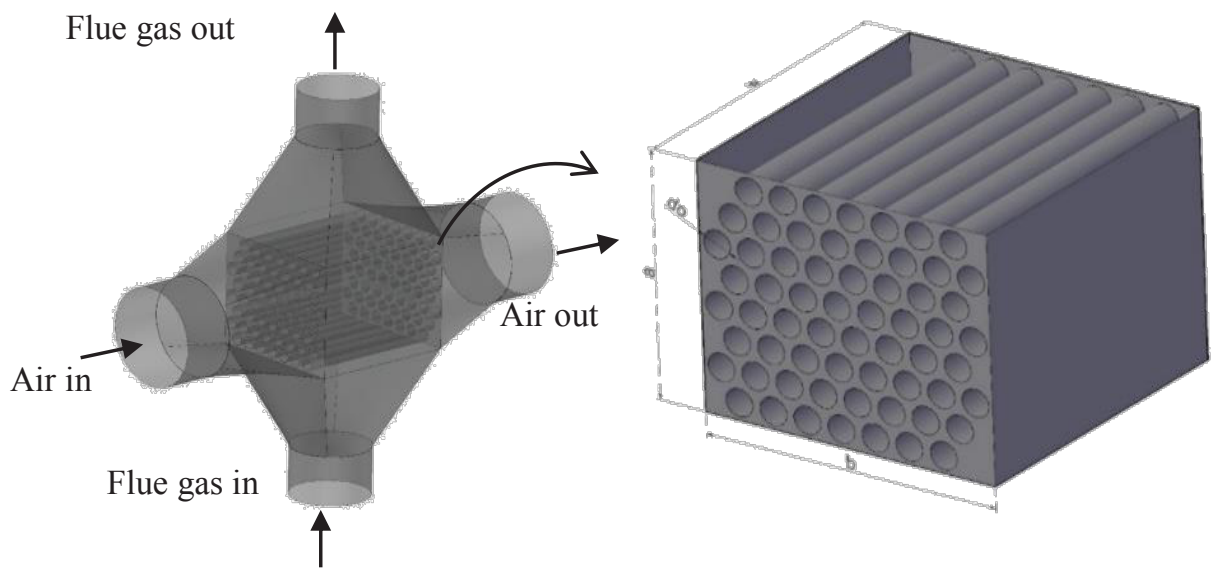

Fig. 1. Tube bank heat exchanger

The mathematical model of FGAHE is based on Logarithmic mean temperature difference (LMTD) concept which will be defined subsequently. First of all, an input design parameter need to be defined as listed in Table 1. 
Table 1. Input design parameters

\begin{tabular}{|l|c|c|c|}
\hline \multicolumn{1}{|c|}{ Parameter } & Symbol & Value & Unit \\
\hline Outer diameter & $d_{o}$ & 0.5 & in \\
\hline Inner diameter & $d_{i}$ & 0.43 & in \\
\hline Heat required for desiccant regeneration & $Q_{g}$ & 531 & $\mathrm{~W}$ \\
\hline Drying heat & $Q_{d}$ & 102.2 & $\mathrm{~W}$ \\
\hline Volume flow rate of air & $\dot{V}_{a}$ & 57 & $\mathrm{~m} 3 / \mathrm{hr}$ \\
\hline Temperature of air in & $T_{a i}$ & 303.15 & $\mathrm{~K}$ \\
\hline Temperature of air out & $T_{a o}$ & 333.15 & $\mathrm{~K}$ \\
\hline Density of air & $\rho_{a}$ & 1.2 & $\mathrm{~kg} / \mathrm{m}^{3}$ \\
\hline Thermal conductivity of pipe wall & $k_{w}$ & 45 & $\mathrm{~W} / \mathrm{m} . \mathrm{K}$ \\
\hline Mass flow rate of air & $\dot{m}_{a}$ & 0.0176 & $\mathrm{~kg} / \mathrm{s}$ \\
\hline
\end{tabular}

All the physical properties of air $\left(v_{a}, \rho_{a}, \operatorname{Pr}_{a}, K_{a}\right)$ are taken at the average temperature $(\mathrm{Ta})$ between the in temperature and out temperature as $T a=(T a i+T a o) / 2$. The flue gas properties are defined as in Table 2.

Table 2. Flue gas properties

\begin{tabular}{|l|c|c|c|}
\hline \multicolumn{1}{|c|}{ Input } & Symbol & Value & Unit \\
\hline Prandtl number & $P r_{f}$ & 0.7 & - \\
\hline Thermal conductivity & $k_{f g}$ & 0.037 & $\mathrm{~W} / \mathrm{m}+\mathrm{K}$ \\
\hline Kinematic viscosity of the flue gas & $v_{f}$ & $32.8 * 10^{-6}$ & $\mathrm{~m}^{2} / \mathrm{s}$ \\
\hline Specific heat capacity of flue gas & $C p_{f}$ & 1097 & $\mathrm{~J} / \mathrm{kg} \cdot \mathrm{K}$ \\
\hline Mass flow rate of the flue gas & $\dot{m}_{f g}$ & 0.0044 & $\mathrm{~kg} / \mathrm{s}$ \\
\hline Density of flue gas & $\rho_{f}$ & 1 & $\mathrm{~kg} / \mathrm{m}^{3}$ \\
\hline Inlet temperature of flue gas & $T_{f i}$ & 168.8 & ${ }^{\circ} \mathrm{C}$ \\
\hline
\end{tabular}

The outlet temperature of flue gas from FGAHE is calculated based on the actual energy required to regenerate the desiccant material. Temperature distribution along the tubes of FGAHE is expressed by using the concept of (LMTD) given by the following relation

$$
L M T D=\frac{\left(T_{f i}-T_{a o}\right)-\left(T_{f o}-T_{a i}\right)}{\log \left(\frac{T_{f i}{ }^{-T} a o}{T_{f o}-T_{a i}}\right)}
$$

The total heat transfer area is calculated based on the actual heat defined by $Q_{g}$ as given by the following equation

$$
A=\frac{Q_{g}}{U L M T D}
$$

The number of tubes is decided to formulate as follows

$$
n=\frac{A}{L p_{i} d_{i}}
$$

The Nusselt number of the flue gas $\left(N u_{f}\right)$ over a tube bank heat exchanger for staggered arrangement is given by [18]

$$
\begin{array}{cc}
N u_{f}=1.04 \operatorname{Cn}\left(\operatorname{Re}_{f}\right)^{0.4}\left(\operatorname{Pr}_{f}\right)^{0.36}\left(\frac{\operatorname{Prf}}{\operatorname{Prw}}\right)^{0.24} & \text { at } 500 \leq R e_{f} \geq 1 \\
N u_{f}=0.71 C_{n} \operatorname{Ref}^{0.5} \operatorname{Pr} f^{0.36}\left(\frac{\operatorname{Prf}}{\operatorname{Prw}}\right)^{0.24} & \text { at } 1000 \leq R e_{f}>500 \\
N u_{f}=0.35 C_{n} \operatorname{Ref}^{0.6} \operatorname{Prf}^{0.36}\left(\frac{\operatorname{Prf}}{\operatorname{Prw}}\right)^{0.24}\left(\frac{X t}{X l}\right)^{0.2} & \text { at } 2 \times 10^{5} \leq R e_{f}>1000
\end{array}
$$




$$
N u_{f}=0.031 C_{n}\left(R e_{f}\right)^{0.8} \operatorname{Pr}_{f}^{0.36}\left(\frac{P r f}{P r w}\right)^{0.24}\left(\frac{X_{t}}{X_{l}}\right)^{0.2} \quad \text { at } 2 \times 10^{6} \leq \operatorname{Ref}>2 \times 10^{5} \text { (7) }
$$

The Nusselt number of air $\left(N u_{a}\right)$ inside the tube of heat exchanger is expressed by [18]

$$
N u_{a}=4.364\left\{\left[1+\left(\frac{G_{Z}}{29.6}\right)^{2}\right]^{\frac{1}{6}}\right\}\left\{1+\left[\frac{G_{z}}{\left(19.04 *\left(1+\left(\frac{P r_{a} T_{a}}{0.0207}\right)^{\frac{2}{3}}\right)^{0.5} *\left(\frac{G_{Z}}{29.6}\right)^{2}\right)^{\frac{1}{3}}}\right\}^{\frac{3}{2}}, G z=\left(\frac{\pi}{4}\right) \frac{R e_{a} P r_{a}}{\frac{L}{d_{o}}}\right.
$$

The length of tube is related to the cross section of FGAHE $\left(A_{c H E}\right)$ which assumed to be square in shape.

$$
L=\sqrt{A_{c H E}}
$$

Convection heat transfer coefficient $(\mathrm{h})$ is given as follows

$$
h=N u \frac{K}{d}
$$

The thermal resistances through the air layer $\left(T R_{a}\right)$, wall $\left(T R_{w}\right)$ and flue gas layer $\left(T R_{f g}\right)$ are expressed as follows

$$
T R_{a}=\frac{1}{A_{a} h_{a}}, T R_{w}=\frac{\ln \left(\frac{d_{o}}{d_{i}}\right)}{2 \pi L K_{w}}, T R_{f g}=\frac{1}{A_{f g} h_{f g}}
$$

The overall heat transfer coefficient is computed as given below

$$
U=\frac{1}{A\left(T R_{f} g+T R_{W}+T R_{a}\right)}
$$

\section{Algorithm}

The mathematical model of FGAHE is solved using a computer code built by MATLAB R2017a. The algorithm of this code stats with guessing the value of overall heat transfer coefficient. The new value of the overall heat transfer coefficient then is calculated based on the thermal resistance and heat transfer area. The code checks the convergent of solution until 10-6 accuracy.

\section{Results and discussion}

This work discusses the design results of flue gas-air heat exchanger (FGAHE) for heat recovery from biomass waste energy to regenerate desiccant material for air drying purpose. The results include the effect of copper tube outer diameter on the design parameters. The design parameters of FGAHE is represented by the heat transfer area, copper tube length and number of tubes while the performance parameters involve overall heat transfer coefficient and heat exchanger effectiveness.

The outer diameter of copper tubes which configures the tube bank of FGAHE is an important input parameter that required to be investigated from different design aspects. The effect of tube diameter on heat transfer area which is an influential design parameter is shown in Figure 2. The heat transfer area increases with the increase of tube diameter in approximately linear relation. Also, the tube length augments as tube diameter raises as illustrated in Figure 3. 


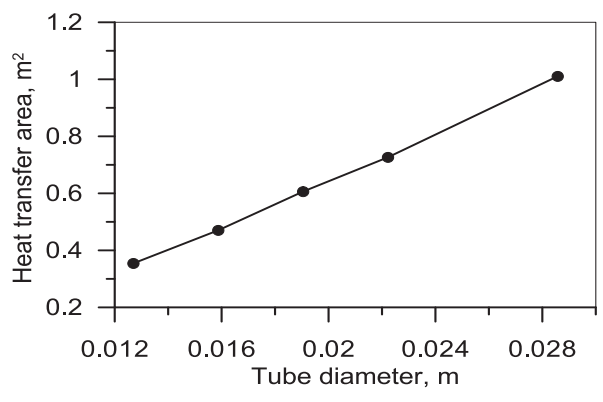

Fig. 2 The effect of tube diameter on heat transfer area.

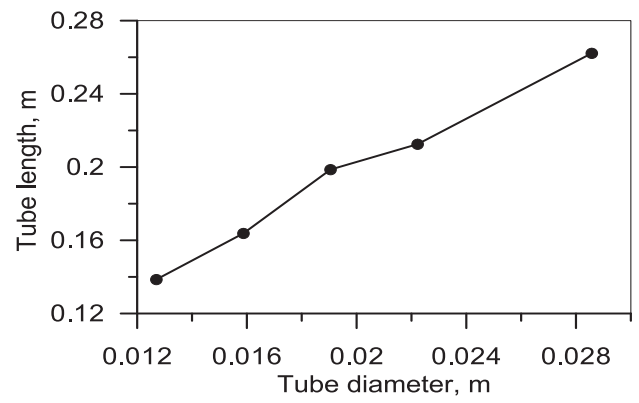

Fig. 3. The effect of tube diameter on tube length.

The performance aspect of FGAHE can be understood when showing the effect of tube diameter on overall heat transfer coefficient which presented in figure 4 Obviously, the increasing in tube diameter leads to reduction in overall heat transfer coefficient and this causes the increasing in heat transfer area which discussed previously. Same story can be told by the Nusselt numbers in both flue gas and air sides as depicted in figure 5 However, the difference in Nusselt number gradient has occurred due to different flow conditions in flue gas over the tube bank and air inside the tubes.

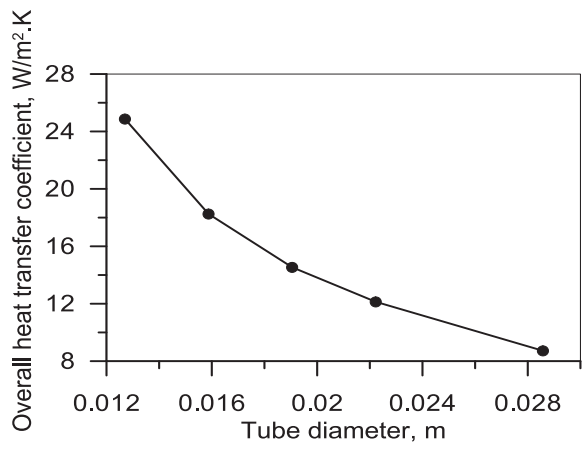

Fig. 4 The effect of tube diameter on overall heat transfer coefficient

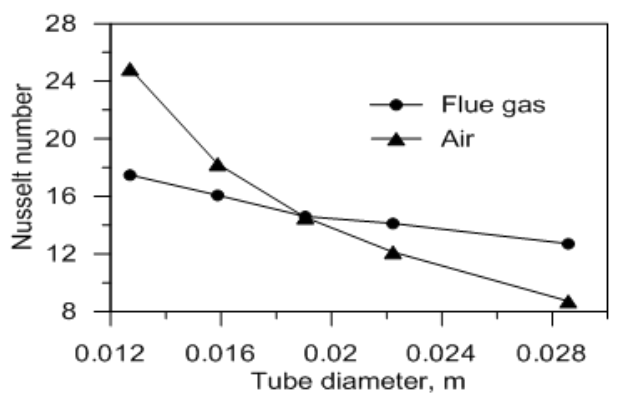

Fig. 5. The effect of tube diameter on Nusselt number.

\section{Conclusion}

The present work exhibits the impact of tube diameter in a gas to gas heat exchanger on thermal performance of FGAHE for recovering thermal waste in flue gases. The FGAHE has been designed based on LTMD method as a tube bank gas-gas heat exchanger. The results have showed that the tube diameter has a significant influence on the design aspects represented by heat transfer area, tube length and number of tubes. The smaller tube diameter leads to smaller heat transfer area and tube length. On the other hand, the overall heat transfer coefficient and Nusselt numbers have larger rates at smaller tube diameter. In conclusion, the chosen tube diameter for the current FGAHE is the smaller diameter of $0.0127 \mathrm{~m}$ due to the high thermal performance. 


\section{Nomenclature}

\begin{tabular}{|c|c|c|}
\hline SYMBOL & NAME & UNIT \\
\hline$A$ & Heat transfer area & $\mathrm{m}^{2}$ \\
\hline $\mathrm{A}_{\mathrm{cHE}}$ & Area of heat exchanger & $\mathrm{m}^{2}$ \\
\hline $\mathrm{d}_{\mathrm{i}}$ & Inner diameter & $\mathrm{m}$ \\
\hline $\mathrm{d}_{\mathrm{o}}$ & Outer diameter & $\mathrm{m}$ \\
\hline $\mathrm{h}_{\mathrm{a}}$ & Heat transfer coefficient of air & $\mathrm{W} / \mathrm{m}^{2} \cdot \mathrm{k}$ \\
\hline $\mathrm{h}_{\mathrm{fg}}$ & Heat transfer coefficient of flue gas & $\mathrm{W} / \mathrm{m}^{2} \cdot \mathrm{k}$ \\
\hline$K$ & Thermal Conductivity of wall & $\mathrm{W} / \mathrm{m} \cdot \mathrm{k}$ \\
\hline $\mathrm{L}$ & Length of heat exchanger & $\mathrm{m}$ \\
\hline$m_{\mathrm{fg}}$ & Mass flow rate of the flue gas side & $\mathrm{kg} / \mathrm{s}$ \\
\hline $\mathrm{Re}_{\mathrm{a}}$ & Reynolds number of air & - \\
\hline $\mathrm{Re}_{\mathrm{f}}$ & Reynolds number of flue gas & - \\
\hline $\mathrm{T}_{\mathrm{fo}}$ & Temperature of flue gas out & ${ }^{\circ} \mathrm{C}$ \\
\hline
\end{tabular}

The authors acknowledge Universiti Teknologi PETRONAS for supporting the research as the first author receives a financial support for her PhD study under Graduate assistance scheme (GA). Also, appreciations are due to Ministry of Higher Education MOHE in Malaysia for utilizing the FRGS grant under CS: 0153AB-K81.

\section{References}

1. N. Goel, Lehigh University (2012).

2. F. Li, L. Du, Fu. Li, Z. Xi., Procedia Engineering. 146, 9. (2016)

3. Y. M. Yunus, H. H. Al-Kayiem, and K. Albaharin, Journal of Applied Sciences 11, 9 (2011)

4. S. Misha, S. Mat, M. H. Ruslan, E. Salleh, K. Ksopian., Solar Energy 112, 10 (2015)

5. K. J. Chua, Applied Thermal Engineering 89, 13(2015)

6. I. Gerken, J. J. Brandner, and R. Dittmeyer., Applied Thermal Engineering 93,13 (2016)

7. H. Li, Q. Chen, X. Zang, K. N. Finney., Applied Thermal Engineering 35, 9 (2012)

8. S. Ferreira, B. and P. Pilidis. Journal of energy resources technology 123, 5 (2001)

9. R. Thakar, S. Bhosle, and S. Lahane., Procedia Manufacturing 20, 4 (2018)

10. E. Wang, L. K. H. Naveed, L. De, M. Jindamau, W. Wu, Y. Tianwei, Applied Thermal Engineering 141 (2018)

11. N. Komninos, and E. Rogdakis, Applied Thermal Engineering 133, 14 (2018)

12. B. Cardenas, S. D. Garvey, B. Kanthavaj, M. C. Simpson. 14, 10 (2017)

13. A. Macháčková, R. Kocich, M. Bojiko, L. Kuncucka, K. Poiko., International Journal of Heat and Mass Transfer, 124, 12 (2018).

14. B. Cárdenas, S. D. Garvey, B. Kanthavaj, M. C. Simpson., Journal of Energy Storage (2017)

15. O. Ipek, B. Kiliç, and B. Gürel. 124, (2017)

16. N. H. Abu-Hamdeh, and K.H. Almitani, Solar Energy 134. (2016)

17. Y. Jiang, T. Ge, and R. Wang, Energy and Buildings 65. (2013)

18. A. Bejan, Heat transfer. 1993. John Wiley \& Sons Inc, (1971). 